\title{
MICROSTRUCTURAL ANALYSIS OF 1100 AI CLAD 5083 AI BY FRICTION STIR PROCESSING
}

\author{
KANNAN GANESA BALAMURUGAN
}

Department of Mechanical Engineering, IFET College of Engineering, Villupuram, Tamil Naud-605108, India

ABSTRACT
Friction stirprocessingis an unique surface modification process for non-ferrousmetals. Especially for aluminum and
itsalloys.In thispresentwork, Al 1100 commercially pure aluminium alloywasclad over Al 5083 aluminium alloy friction
stirprocessing. Toolroational speed and travel speed are processparameters. Effect of the processparameters on
microstructure of Al clad composites are investigated
KEYWORDS: Geographical Indications, Marketing Management, Intellectual Property Rights, Product Differentiation,
GI Registration

Received: Jun 08, 2020; Accepted: Jun 28, 2020; Published: Aug 21, 2020; Paper Id.: IJMPERDJUN2020857

\section{INTRODUCTION}

Friction stirprocess is worked on the basic principles of friction stirwelding process (FSW) created in view of the essential standards of friction blend welding (FSW), a strong state Joining process initially produced for aluminum amalgams (alloys), is a rising metal working system that can give limited alteration and control of microstructures in close surface layers of hand led metallic segments. The FSP causes extreme plastic deformation, material mixing, and thermal exposure, bringing about huge microstructural refinement, densification, and homogeneity of the prepared zone. The FSP procedure has been effective lyutilized for creating the fine-grained structure and surface composite, altering the microstructure of materials, and combining the composite and intermetallic compound in situ.FSW.

Chen et al. [1] investigated the effect of stirredintermetallics Al-Fe-Si particles by friction stirprocessing on structure and corrosion resistance of MAO coated Al6061 aluminium alloy. The results revealed that the coarse and congregated Al-Fe-Si particles lead to large microvoids at the interface of the MAO and substrate. The corrosion properties of the MAO coating have been improved after FSP due to refining and uniform distribution of Al-Fe-Si particles in the coating.

Din et al. [2] investigated the corrosion behaviors of steam based conversion coating containing TiO2particles on Al-Mg-Si grade aluminium alloy. The results showed that the presence of TiO2enhanced the corrosion resistance of coating.

$\mathrm{Hu}$ et al. [3] triedcerium tartrate as new pigment in epoxycoating on aluminium alloys. The result sshowed that the cerium tartrate was an effective pigment for improving the barriereffect of epoxycoating on aluminium alloys.

Wojciechowski et al. [4] anodized aluminium in oxalic and sulphuricacid solutions. Silane coatingalsoapplied over them. The resultsrevealedthat the silane coated aluminium showedimproved corrosion resistance. The best anticorrosivecoatingwasreportedwithunsealed pores samples. 
Surca et al. [5] investigated the protective behavior of bis-(3-(3-(3triethoxysilyl)propyl)thioureido)propylterminatedpolydimethylsiloxane (PDMSTU) pre-treatmentcoatings on AA 2024 aluminium alloy. The electrochemicalexperimentsshowedthat the presence of BTESPT and TS-iOc7-POSS moleculesimproves the protective behaviour of the silane coating, while Raman imagingwasused to determinetheir distribution in coatings.

Plagemann et al. [6] attemptedzin-magnesium-pigment richcoating on aluminium alloys. In the presented investigations corrosion protection coatingsbased on intermetallic zinc-magnesium pigments weretested. This approachwasbased on the idea to combine the cathodic protection of magnesium pigments with the better handling and application properties of zinc, due to itslowerreactivity. Salt spray tests showed a superior protection behavior for the tested pigments with zinc contents of lessthan $80 \mathrm{wt} \%$ in comparison to pure zinc and magnesiumreferences. The pigment composition of $74 \mathrm{wt} \%$ zinc proved to beespeciallyadvantageous.Presentworkinvestigates the effect of processparamtersliketooltravel speed and toolrotational speed on the microstructre of the Al 11100 clad Al 5083 aluminium structures.

\section{EXPERIMENTAL PROCEDURE}

The commercially pure Al 1100 aluminium alloywasselected as cladmaterial and A15083 aluminium alloywasselected as susbtrate. Both aluminium alloysweremachined to 50 x $50 \mathrm{~mm} 2$ plate. Substratematerialwaskept as $5 \mathrm{~mm}$ thick plate and clad as $1 \mathrm{~mm}$ thickness. A FSP tool of $18 \mathrm{~mm}$ shoulderdiameter and $5 \mathrm{~mm}$ diameter pin. Pin lengthwaskept as 5 mm.Toolmaterialwas High Chromium High Carbonalloy ( $\mathrm{HCHCr}$ ). Al1100 stripwasinsertedinto the machined groove in Al5083 and the assemblywasfixed to the FSP machine table usingsuitablefixtures. The FSP toolwasfixed to the spindle and tightened.The FSP machine wasprogrammedwithpresetprocessparameter values and activated.The rotating FSP toolplunges at Al1100region and passes through Al5083 region. This wasresulted in bonding of Al1100 with Al5083 alloy.Thentooltook an offset of radius of itsshoulderdiameter and plungedagaininto the materials and performed friction stircladdingtechnique.Likewise four parallel passes wereconducted.The sameprocedurewasfollowed for otherprocessparameter sets. The processparameters are show in the Table 1.

Sampleswere cross sectioned and prepared for microstructural analysis. Sampleswereethchedwith Keller reagent. Optical microscopywasadopted to analysis the microstructre.

Table 1: FSP Process Parameters

\begin{tabular}{|c|c|}
\hline Tool Rotational Speed (RPM) & Tool Travel Speed (mm/min) \\
\hline
\end{tabular}

\begin{tabular}{l|r}
$700,800,900$ & 15,30
\end{tabular}

\section{RESULTS AND DISCUSSIONS}

Microstructure of Al1100 clad Al5083 aluminium alloy 


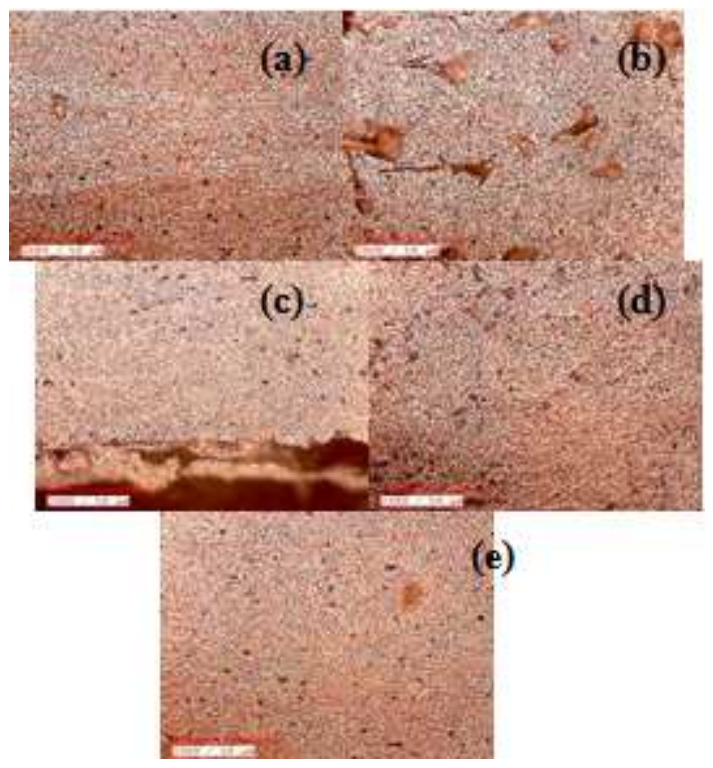

Figure 1: Microstructre of Al Clad Sample $700 \mathrm{rpm}$ and $15 \mathrm{~mm} / \mathrm{min}$.

Fig.1a: Shows the bottom parent metal microstructure withparallel grain flow along the direction of rolling. The fine grains of $\mathrm{Mg}_{2} \mathrm{Si}$ in primary aluminium phase in the same direction.

Fig.1b: Shows the heataffected zone with thermo mechanical transformation leading to increasedplasticity and flow in direction of the toolnear the nugget zone.

Fig. 1c: Shows the nugget zone with insoluble inter metallicprobablyAl6(Fe, Mn) in fragmented grains of AA1100 and with AA 5083.

Fig 1d: Shows the bottom interface zone between the $1100 \& 5083$. The zone to the width of the nugget zone showncomplete fusion and the exchange of constituents of $1100 \& 5083$.

Fig. 1e: Shows the shoulder zone at the 1100 sidewithfragmented grains and insoluble inter metallics.

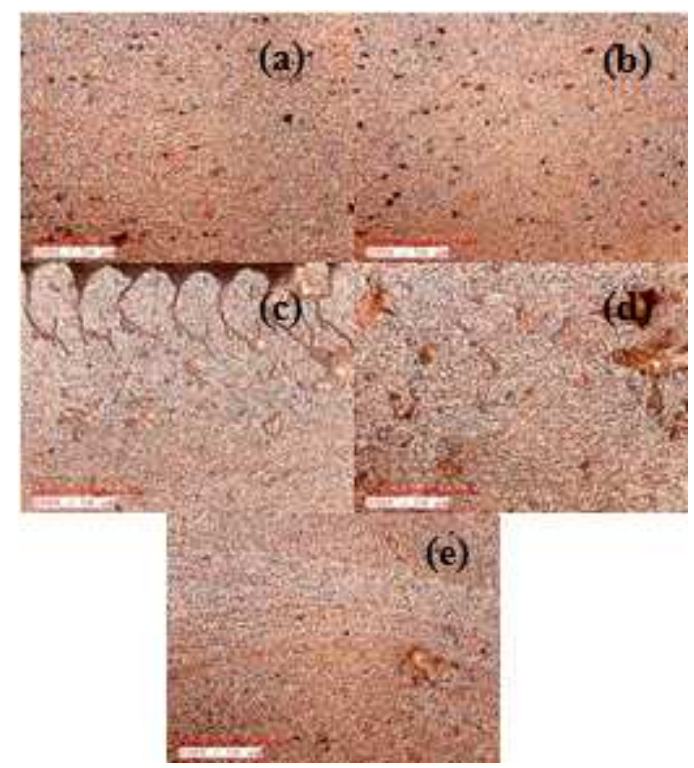

Figure 2: Microstructre of Al Clad Sample $700 \mathrm{rpm}$ and $30 \mathrm{~mm} / \mathrm{min}$. 
Fig.2a: Shows the bottom parent metal microstructure withparallel grain flow along the direction of rolling. The fine grains of $\mathrm{Mg}_{2} \mathrm{Si}$ in primary aluminium phase in the same direction.

Fig.2b: Shows the heataffected zone with thermo mechanical transformation leading to increasedplasticity and flow in direction of the toolnear the nugget zone.

Fig. 2c: Shows the nugget zone with insoluble inter metallicprobablyAl6(Fe, Mn) in fragmented grains of AA1100 and with AA 5083.

Fig.2d: Shows the bottom interface zone between the $1100 \& 5083$. The zone to the width of the nugget zone showncomplete fusion and the exchange of constituents of $1100 \& 5083$,

Fig.2e: Shows the shoulder zone at the 1100 sidewithfragmented grains and insoluble inter metallics.

Fig.3a: Shows the parent metal 1100 at top of the claddingwithonlyprimary phase withsecondary as impurity.

Fig.3b: Shows the bottom AA 5083 with grain orientation along the direction of formingwith Mg2Si in primary aluminium matrix.Shows the heataffected zone with thermo mechanical transformation leading to increasedplasticity and flow in direction of the toolnear the nugget zone.

Fig.3c : Shows the shoulder zone at the 1100 sidewithfragmented grains and insoluble inter metallics.

Fig.3d: Shows the nugget zone with insoluble inter metallicprobablyAl6(Fe, Mn) in fragmented grains of AA1100 and with AA 5083. The matrix has both the constituents of AA 1100 \& AA 5083.

Fig.3e: Shows the bottom interface zone between the $1100 \& 5083$.The zone to the width of the nugget zone showncomplete fusion and the exchange of constituents of $1100 \& 5083$,

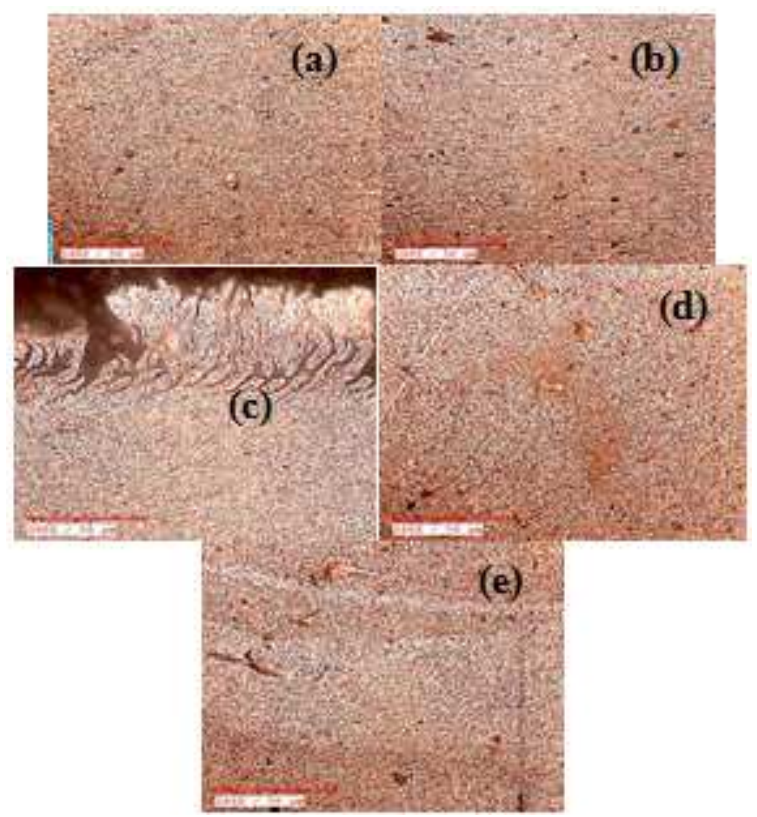

Figure 3: Microstructreof Al Clad Sample $800 \mathrm{rpm}$ and $15 \mathrm{~mm} / \mathrm{min}$.

Fig.4a: Shows the bottom AA 5083 withgrqain orientation along the direction of formingwith $\mathrm{Mg}_{2} \mathrm{Si}$ in primary aluminium matrix. 
Fig.4b: Shows the shoulder zone at the 1100 sidewithfragmented grains and insoluble inter metallics. The matrix isdominantlywithconstituents of AA 1100.

Fig.4c: Shows the shoulder zone at the 1100 sidewithfragmented grains and insoluble inter metallics.

Fig.4d: Shows the nugget zone with insoluble inter metallicprobablyAl6(Fe, Mn) in fragmented grains of AA1100 and with AA 5083. The matrix has both the constituents of AA 1100 \& AA 5083.

Fig.4e: Shows the right side parent metalwith dominant microstructure of AA 5083.

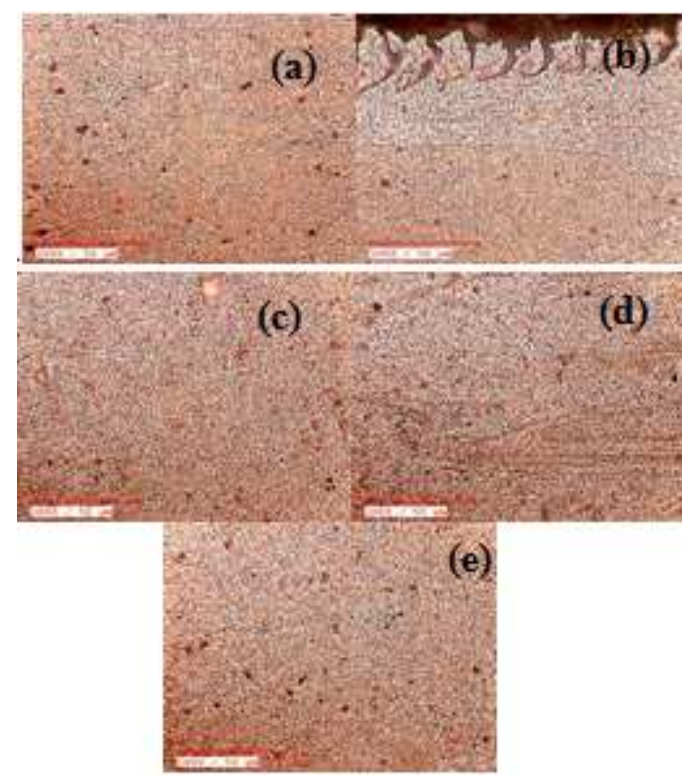

Figure 4: Microstructre of Al Clad Sample $800 \mathrm{rpm}$ and $30 \mathrm{~mm} / \mathrm{min}$.

Fig1: Shows the parent metal AA 5083 leftsidewith microstructure identical of parent AA 5083.

Fig2: Shows the first interface zone of the cladded AA 1100 \& 5083. Leftis 5083 \& right is AA 1100.

Fig3: Shows the shoulder zone at the 1100 sidewithfragmented grains and insoluble inter metallics.

Fig4: Shows the heataffected zone of 5083 near the cladding zone with insolubles and Mg2Si particles. This zone is at the leftside

Fig5: Shows the heataffected zone of 5083 near the cladding zone with insolubles and $\mathrm{Mg} 2 \mathrm{Si}$ particles. This zone is at the right side.

Fig6: Shows the cladded AA1100 \& AA 5083 at the interface zone. The fusion zone does not show anydiscontinuity and effective and verythin at the interface. 


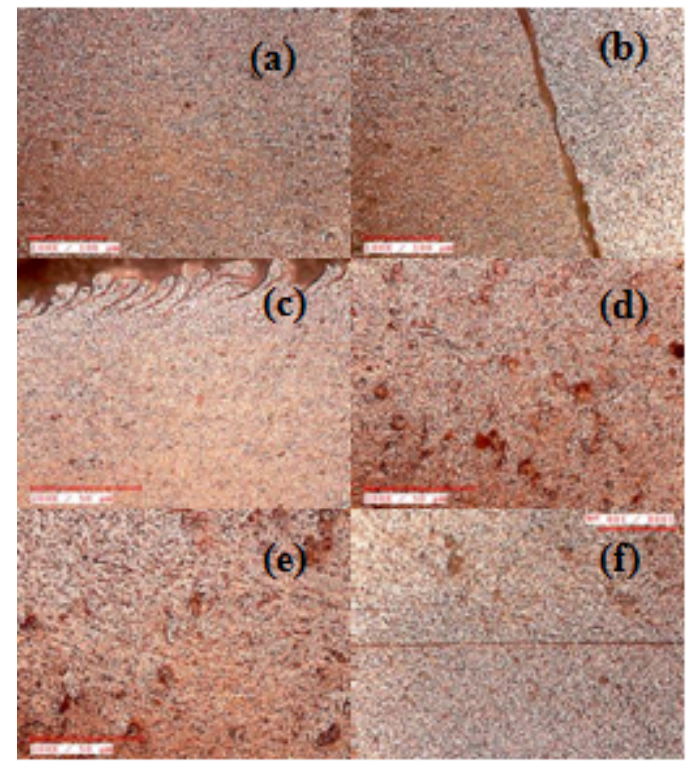

Figure 5: Microstructre of Al Clad Sample $800 \mathrm{rpm}$ and $30 \mathrm{~mm} / \mathrm{min}$.

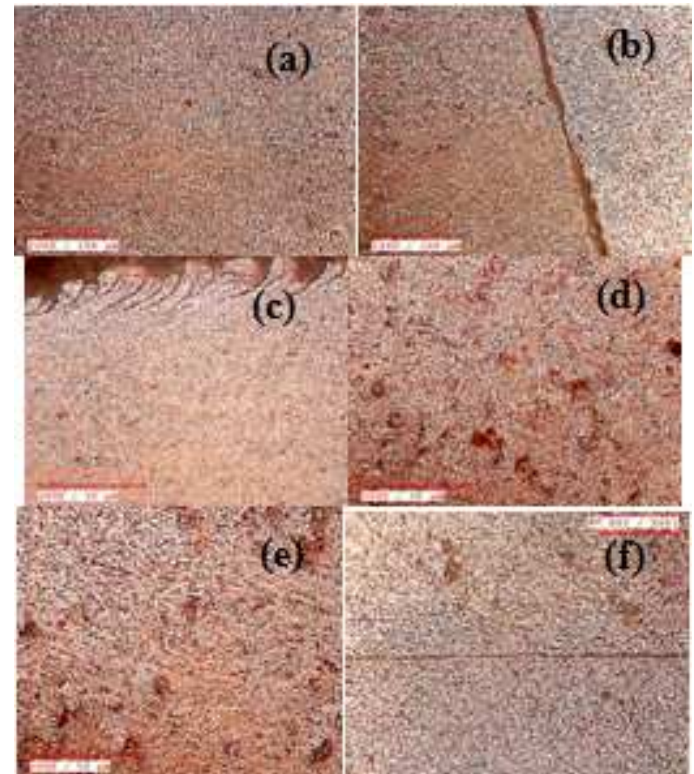

Figure 6: Microstructre of Al Clad Sample $900 \mathrm{rpm}$ and $15 \mathrm{~mm} / \mathrm{min}$.

Fig.6a: Shows the parent metal AA 5083 leftsidewith microstructure identical of parent AA 5083.

Fig.6b: Shows the first interface zone of the cladded AA 1100 \& 5083. Leftis 5083 \& right is AA 1100.

Fig.6c: Shows the shoulder zone at the 1100 sidewithfragmented grains and insoluble inter metallics.

Fig.6d: Shows the heataffected zone of 5083 near the cladding zone with insolubles and Mg2Si particles. This zone is at the leftside

Fig.6e: Shows the heataffected zone of 5083 near the cladding zone with insolubles and Mg2Si particles. This zone is at the right side.

Fig.6f: Shows the cladded AA1100 \& AA 5083 at the interface zone. The fusion zone does not show anydiscontinuity and effective and verythin at the interface. 


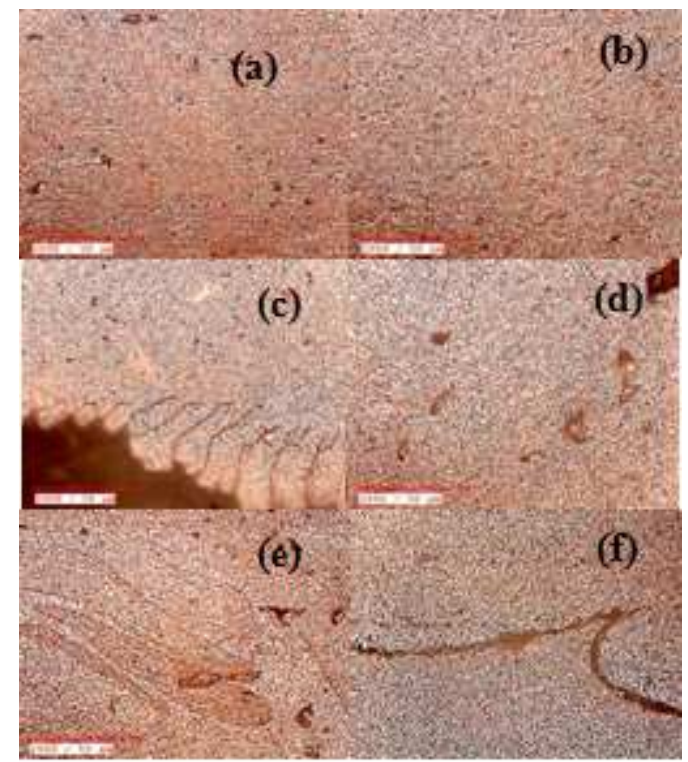

Figure 7: Microstructre of Al Clad Sample $900 \mathrm{rpm}$ and $30 \mathrm{~mm} / \mathrm{min}$.

Fig.7a: Shows the parent metal AA 5083 left side with microstructure identical of parent AA 5083.

Fig.7b: Shows the heataffected zone of 5083 near the nugget zone/cladding zone.

Fig.7c: Shows the shoulder zone at the 1100 side with fragmented grains and insoluble inter metallics.

Fig.7d: Shows the nugget zone of the AA 1100 with fragmented grains primarilywith Aluminium alpha phase.

Fig.7e: Shows the heataffected zone of 5083 near the cladding zone with insolubles and Mg2Si particles. This zone is at the right side.

Fig.7f: Shows the cladded AA1100 \& AA 5083 at the interface zone. The fusion zone does not show any discontinuity and effective and very thin at the interface.

\section{CONCLUSIONS}

In this work, the commercially pure Al 1100 aluminium alloy was clad over Al 5083 aluminium alloy by friction stir processing. Effect of process parameters like tool travel speed and tool rotational speed on the microstructure was investigated. Following conclusions are drawn from this investigation.

- In both $700 \mathrm{rpm} 15 \mathrm{~mm} / \mathrm{min}$ and $30 \mathrm{~mm} / \mathrm{min}$ samples,bottom parent metal microstructure showsparallel grain flow along the direction of rolling. The fine grains of $\mathrm{Mg}_{2} \mathrm{Si}$ in primary aluminium phase in the same direction.

- In both $700 \mathrm{rpm} 15 \mathrm{~mm} / \mathrm{min}$ and $30 \mathrm{~mm} / \mathrm{min}$ samples, the nugget zone contains insoluble inter metallicprobablyA16(Fe, Mn) in fragmented grains of AA1100 and with AA 5083.

- In both $800 \mathrm{rpm} 15 \mathrm{~mm} / \mathrm{min}$ and $30 \mathrm{~mm} / \mathrm{min}$ samples, microstructre shows the shoulder zone at the 1100 sidewithfragmented grains and insoluble inter metallics.

- In 800 rpmsamples, the heataffected zone of 5083 near the cladding zone contains insolubles and Mg2Si particles.

- Samplesclad at 900 rpmdoes not show anydiscontinuity and effective and verythin at the interface. 


\section{REFERENCES}

1. Ming-an Chen, Yan-chun Ou, You-hong Fu, Zai-hua Li, Jun-ming Li, Sheng-dan Liu, "Effect of friction stirred Al-Fe-Si particlesin 6061 aluminumalloy on structure and corrosion performance of MAO coating”, Surface \&CoatingsTechnology 304 (2016) 85-97.

2. Rameez Ud Din, Visweswara C. Gudla, Morten S. Jellesen, RajanAmbat, “ Microstructure and corrosion performance of steam-based conversion coatingsproduced in the presence of TiO2 particles on aluminium alloys", Surface \&CoatingsTechnology 296 (2016) 1-12.

3. Devireddy, K. R. I. S. H. N. A. J. A., et al. "Analysis of the influence of friction stirprocessing on gastungsten arc welding of 2024 aluminumalloyweld zone." Int. J. Mech. Prod. Eng. Res. Dev 8.1 (2018): 243-252.

4. Tianhui Hu, HongweiShi, Shihua Fan, Fuchun Liu, En-Hou Han, “ Cerium tartrate as a pigment in epoxycoatings for corrosion protection of AA 2024-T3”, Progress in Organic Coatings 105 (2017) 123-131.

5. Swaminathan, G., and S. Sathiyamurthy. "ExperimentalStudy of Mechanical and MetallurgicalProperties of Friction StirWeldedDissimilarAluminumAlloys." Int. J. Mech. Prod. Eng. Res. Dev. (2018): 1049-1058.

6. Jarostaw Wojciechowski, Karol Szubert, Ralf Peipmann, Mathias Fritz, Udo Schmidt, Andreas Bund, GrzegorzLota, “ Anticorrosiveproperties of silane coatingsdeposited on anodised aluminium”, Electrochimica Acta 220 (2016) 1-10.

7. Shubhavardhan, R. N. "Microstructure and TensileStrength of Friction StirWelding of Al-Cu." International Journal of Mechanical and Production Engineering Research and Development (IJMPERD) 5.2 (2015): 41-50.

8. Angelja K. Surca, Aleksander Rauter, MirjanaRodo`sek, LidijaSlemenikPer`se,Matja`zKo`zelj, Boris Orel, “ Modified bis-(3(3-(3-triethoxysilyl)propyl)thioureido)propylterminated poly(dimethylsiloxane)/POSS protective coatings on AA2024", Progress in OrganicCoatings 103 (2017) 1-14.

9. Abolusoro, Olatunji P., and Esther T. Akinlabi. "Wear and corrosion behaviour of friction stirwelded aluminium alloys-an overview." Int J MechProd Eng Res Dev 9 (2019): 967-82.

10. Peter Plagemann, Joerg Weise, Anja Zockoll, “ Zinc-magnesium-pigment richcoatings for corrosion protection of aluminumalloys", Progress in OrganicCoatings 76 (2013) 616- 625. 